\title{
The design of free activities for teaching science: A study with preservice teachers
}

\author{
María Puig-Gutiérrez, ${ }^{1 \mathrm{a}}$ and Marta Cruz-Guzmán Alcalá ${ }^{1}$ \\ ${ }^{1}$ Departmet of Didactics of Experimental and Social Sciences, Faculty of Education Sciences, Seville \\ University, C/ Pirotecnia s/n, 41013,Seville, Spain
}

\begin{abstract}
This paper studies a science teaching problem related to students in the Bachelor of Preschool Education at the Seville University, Spain. Preservice teachers face difficulties when designing child-guided activities (also called, free activities). This type of tasks is desirable in preschool classrooms, because they promote creativity, observation capacity, inquiry and children autonomy. With the aim of improving the formation in the Bachelor, two university teachers have asked 136 preservice teachers of the third course to design a 'children's corner in their future classroom' about a specific issue related to the science area in preschool education, according to the Spanish legislation. It is shown the headings of the students' report as a result of their work. It has been analyzed the quality of the child-guided designed activities. It has been observed the need of improving the explicit instruction about the design of free activities for the first educational level.
\end{abstract}

Keywords: child-guided activities; preschool education; preservice teachers

\section{Introduction}

To design free activities that allow students to explore the world around them and begin their learning in the scientific area is a key aspect of the formation of preservice teachers. Thus we consider that the corners of work are a good opportunity to carry out these activities and to develop in children basic scientific skills as inquiry thinkining, reasoning or creativity

For this reason, we believe that preservice teachers should have the possibility to design activities with which students reach a more autonomous and independent learning. This could help them in some way to overcome the traditional model of teaching. So in this paper we focus on the quality of the activities preservice teachers design when they are asked to plan free activities.

\footnotetext{
a Corresponding author: mpuig@us.es
} 


\section{Theoretical background}

Several authors claim teachers need to balance both child-guided and adult-directed activities [1]. That is the reason why preservice preschool teachers need to know how to plan both types of activities. In this paper we want to know the quality of the child-guided activities preservice preschool teachers design. Our hypothesis is that there is an educational problem, related to the science teaching, in the Bachelor of Preschool Education at the Seville University, Spain. Preservice teachers could face difficulties when designing child-centered activities (also called, free activities). This type of tasks is desirable in preschool classrooms, because they promote creativity, observation capacity, inquiry and children autonomy.

Child-centered activities have been studied in preschool research. It has been seen [2] that teachers' use of child-centred approaches affected pupils' acquisition of science skills in schools. Also, child-centered classroom strategies, as thinking routines, develop positive attitudes in children toward thinking and learning. In literature there are examples of childcentered activities [3] that grounded children's understanding.

It could be difficult for preservice teachers, who have lived a traditional teaching model, to design effective free activities in the learning process of their pupils, as teachers tend to teach in the same way they have been taught [4]. This could be one of the reasons why teachers avoid the inquiry activities in the kindergarten class. Besides, it is usual to find preschool preservice teachers thinking children aged 4 to 6 years old are not able to initiate and follow process of science inquiry, although nowadays it is well known that these children are able to build science process skills such as asking questions, formulating hypothesis, observing, classifying, or sorting [5]. Instead of designing high quality free activities, they could plan playful activities, leaving the learning process for further teacherdirected activities. However, a successful free activity is able to promote a meaningful change in the children's ideas, besides to enhance intellectual capacities as important as creativity, or scientific skills as the formulation of hypothesis, planning an inquiry, data analysis, reach conclusions, teamwork, etc. Also, some researchers [6] have found evidence that too much teacher-directed activity undermines young children's self-confidence and motivation to learn.

In this context, we need more research about the difficulties preservice preschool teachers could face when planning child-guided activities, to be able to give them an adjusted quality formation on how to plan child-guided activities, which develop science process skills.

The aim of this paper was to analyze the free activities designed by 136 preservice preschool teachers, who study at the Seville University, in Spain. We wanted to know the quality of these planned activities, searching their potential as children meaningful learning.

\section{Method}

\subsection{Participants and context}

The participants of the study were 136 preservice preschool teachers grouped in small teams. All of them were coursing two coordinated subjects of the third course of the Preschool Bachelor 'Teaching about the Natural Environment (0-6 years old)' and 'Knowledge of the Social Environment'. 


\subsection{Data collection tool}

For data collection, it was used a report made by preservice students. It had seven questions to be answered. The fifth one asks for the design of a minimum of three child-centered and three teacher-directed activities. In this communication, authors analyse the free activities planned by students.

Table 1. Data collection tool.

\begin{tabular}{l}
\hline \multicolumn{1}{c}{ Guide for the children's corner design. } \\
\hline 1. Name of the children's corner \\
2. Age of children \\
3. Importance of the corner's subject, and its learning sense and value \\
4. Setting: Description, materials and resources you need \\
5. Activities (Name, objectives, description, duration, resources) \\
a) Teacher-directed ones (3 or more). A group of pupils are guided by the \\
teacher \\
b) Free activities (3 or more): They are able to be developed without the \\
teacher's guide. \\
6. References (APA 6th Edition) \\
7. Books and stories (3 -4) for the children's corner
\end{tabular}

\subsection{Data analysis instrument}

For the qualitative analysis, it is presented the second instrument, which is based in the child-guided learning characteristics [1]. It has been stablished seven items to assess the quality of every free activity, using a 1 to 4 scale for each item, where 1 shows the greatest disagreement and 4 the greatest agreement. The two authors applied the analysis rubric independently, with the goal of crossing data and reaching consensus on the evaluated items in cases of missing agreement. In this way, it was reached a $100 \%$ of agreement on every item.

Table 2. Data analysis instrument.

Corner's name
Items




\section{Results}

We show the obtained results for each of the evaluated items. Firstly, in Figure 1 are collected the percentages obtained in the first four items.

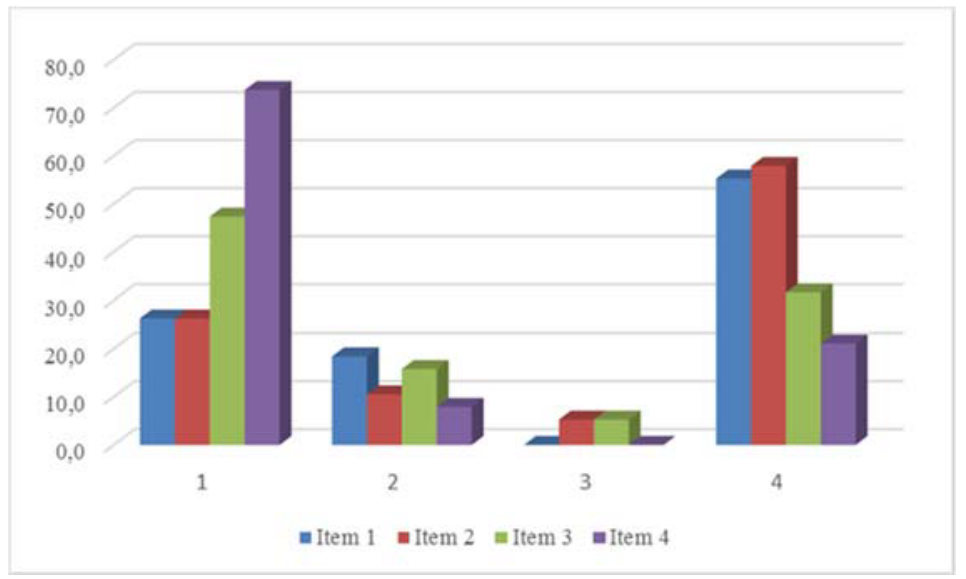

Fig. 1. Results Item 1, 2, 3 and 4.

About the item 1, it is found that the majority of the designed free activities did not meet requirements to be considered as high quality activities. Indeed, just the $50 \%$ of the activities did not require an adult intervention. Therefore, designed free activities showed a high degree of directionality.

On the other hand, the designed free activities not always worked the selected science subject matter from the preschool curriculum stablished by the Spanish educational law (Item 2). More than a 30\% of the activities did not work these selected subject matters, they worked another ones or none.

Another important date is that nearly the $50 \%$ of the cases did not promote the inquiry or material, actions, or ideas exploration (Item 3).

In relation to the possibility that the activity give to pupils to formulate new research questions and apply in new ways the exiting knowledge (Item 4), the results show than $70 \%$ did not encourage pupils to get this goal.

Then, Figure 2 shows the percentages obtained in items 5, 6 and 7.

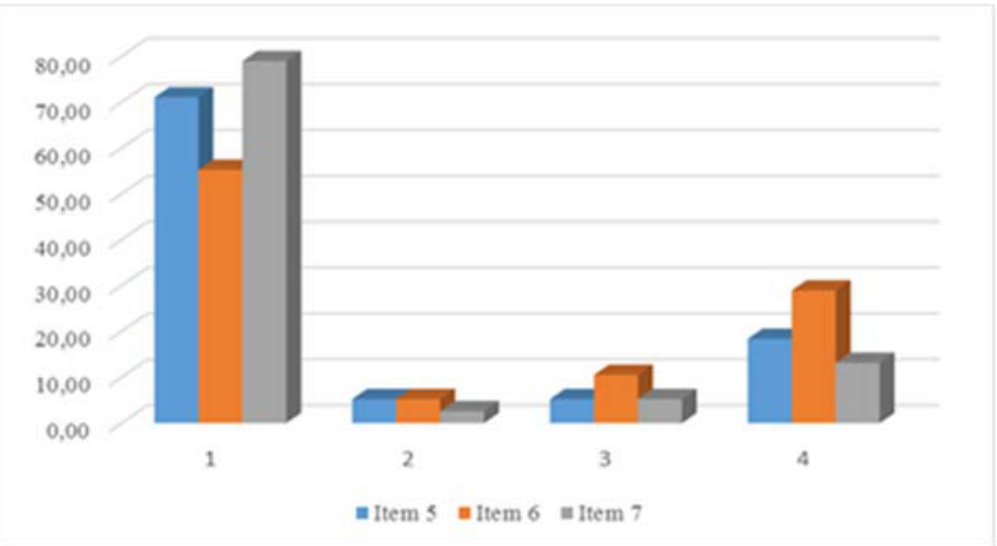

Fig. 1. Results Item 5, 6 and 7. 
As we can see, the results in these three items are not too favourable. Thus, more than $70 \%$ of the activities not motivates children to solve problems by themselves (Item 5 ). In addition, more than $50 \%$ of activities don 't promote the establishment of relationships (Item 6). Finally, the results show that most of the activities $(80 \%)$ did not challenge pupils to reach new skills (Item 7).

\section{Discussion and conclusion}

The studied Spanish preservice preschool teachers tend to plan teacher-directed activities when they are asked to plan child-guided activities, as they have high degrees of directionality in their proposals. The planned activities give children limited possibilities of inquiry or exploration, with serious difficulties for the autonomous learning. In addition, they don 't promote the establishment of relationships between children or the development of new skills in them. This data confirms our initial hypothesis, as preservice teachers have difficulties to design high quality free activities. This could be due to the fact that teachers are reproducing the same model with which they learned [4], using a traditional teaching model where the student is given little chance of experimenting or inquiring independently. On the other hand, the belief of many teachers about the constraints that early-age children have to develop skills linked to scientific research processes [5] may be influencing. Therefore, it is necessary to get deeper in this issue, making specific teaching approaches to guide preservice teachers to design high quality free activities.

\section{References}

1. A. S. Epstein, The Intentional Teacher: Choosing the Best Strategies for Young Children's Learning (2014).

2. N. C. Andiema, JEP, 7(27), 1-9 (2016)

3. M. L. Rönkkö, J.A. Aerila, S. Grönman, IJEC, 48(1), 17-32 (2016)

4. R. M. Pringle, JSTE, 17(3), 291-307 (2006)

5. H. Eshach, M.N. Fried, JSET, 14(3), 315-336 (2005)

6. R. Barnes, Teaching Art to Young Children, (2015) 